\title{
A latinidade de Clarice Lispector: a proposta do escritor perceptor nas crônicas clariceanas
}

\author{
La latinidad de Clarice Lispector: la propuesta del escritor perceptor \\ en las crónicas clariceanas
}

\author{
The latin aspect of Clarice Lispector: the troposal of the perceiver \\ writer in the claricean chronicles
}

Joyce Alves ${ }^{1}$

\begin{abstract}
Resumo
Este artigo é um recorte da tese de Doutorado em Letras, na qual analiso as crônicas de Clarice Lispector publicadas no Jornal do Brasil entre 1967 e 1973, e reunidas no livro A descoberta do mundo em 1984. De modo especial, observo a abordagem feita pela cronista sobre o problema social da fome no Brasil daquela época. Assim, parto da proposta teórica de Walter Mignolo, em Histórias locais / Projetos globais (2003), de que é preciso reconhecer as diferenças epistêmicas. Por meio do que o autor chama de pensamento liminar, é possível romper com o projeto cultural moderno, que há muito propaga a subalternização de saberes e culturas, e identificar os vários loci culturais marcados pela diferença. Daí surge também a ideia de que há um componente perceptor em Clarice Lispector, haja vista que a escritora lança mão do espaço jornalístico para projetar as atenções para o problema social da pobreza e a subnutrição. Na década de 60, Lispector antecipa o que no início do século XXI, críticos como Mignolo, e também Frei Betto (2017), destacariam como proposta epistemológica na percepção de saberes e culturas diferentes. As crônicas clariceanas são, portanto, marcadas pela denúncia e pelo desejo de que tão lacerante problema social se resolva: a fome.
\end{abstract}

Palavras-Chave: Crônicas; Clarice Lispector; cronista perceptor; fome.

\section{Resumen}

Este artículo es un recorte de la tesis de Doctorado en Letras, en la que analizo las crónicas de Clarice Lispector publicadas en el Jornal do Brasil entre 1967 y 1973, y reunidas en el libro El descubrimiento del mundo en 1984. De modo especial, observo el enfoque hecho por la Cronista sobre el problema social del hambre en Brasil de aquella época. Así, parto de la propuesta teórica de Walter Mignolo, en Historias locales / Proyectos globales (2003), de que hay que reconocer las diferencias epistémicas. Por medio de lo que el autor llama pensamiento liminar, es posible romper con el proyecto cultural moderno, que hace mucho propaga la subalternización de saberes y culturas, e identificar los varios loci culturales marcados por la diferencia. De ahí surge también la idea de que hay un componente perceptor en Clarice Lispector, teniendo en cuenta que la escritora lanza mano del espacio periodístico para proyectar las atenciones al problema social de la pobreza y la desnutrición. En la década de 60, Lispector anticipa lo que a principios del siglo XXI, críticos como Mignolo, y también Frei Betto (2017), destacarían como propuesta epistemológica en la percepción de saberes y culturas diferentes. Las crónicas clariceanas son, por tanto, marcadas por la denuncia y por el deseo de que tan lacerante problema social se resuelva: el hambre.

Palabras claves: Crónicas; Clarice Lispector; cronista perceptor; hambre.

\footnotetext{
${ }^{1}$ Doutoranda em Letras; Universidade Estadual de Londrina - UEL; Mestre em Literatura e Práticas Culturais; Londrina, Paraná, Brasil; profejoycecomparada@gmail.com. Trabalho apresentado no I Seminário LatinoAmericano de Estudos em Cultura - SEMLACult, Foz do Iguaçu/PR, Brasil, 2017.
} 


\begin{abstract}
This article is a cut of the doctoral dissertation, in which I analyze the chronicles of Clarice Lispector published in the Jornal do Brasil between 1967 and 1973, and gathered in the book The discovery of the world in 1984. In a special way, I observe the approach made by the Chronicler on the social problem of hunger in Brazil at the time. Thus, I start from the theoretical proposal of Walter Mignolo, in Local Histories / Global Projects (2003), of which it is necessary to recognize the epistemic differences. Through what the author calls the Liminal Thought, it is possible to break with the modern cultural project, which has long propagated the subalternization of knowledge and cultures, and to identify the various cultural loci marked by difference. Hence the idea that there is a perceptive component in Clarice Lispector, given that the writer uses the journalistic space to project attention to the social problem of poverty and malnutrition. In the 1960s, Lispector anticipated what at the beginning of the 21st century, critics such as Mignolo and Frei Betto (2017), would highlight as an epistemological proposal in the perception of different knowledge and cultures. The Claricean chronicles are therefore marked by denunciation and by the desire that such a lacerating social problem be solved: hunger.
\end{abstract}

Keywords: Chronicles; Clarice Lispector; perceptive writer; hunger.

Todo ponto de vista é a vista a partir de um ponto aquele no qual se encontra o leitor. O leitor A não coincide com o lugar sociocultural do leitor B. A mudança de lugar sociocultural provoca mudança de lugar epistêmico.

Frei Betto (2017, p. 97).

Não posso. Não posso pensar na cena que visualizei e que é real. O filho está de noite com dor de fome e diz para a mãe: estou com fome, mamãe. Ela responde com doçura: dorme. Ele diz: mas estou com fome. Ela insiste: durma. Ele insiste. Ela grita com dor: durma, seu chato! Os dois ficam em silêncio no escuro, imóveis. Será que ele está dormindo? - pensa ela toda acordada. E ele está amedrontado demais para se queixar. Na noite negra os dois estão despertos. Até que, de dor e cansaço, ambos cochilam, no ninho da resignação. E eu não aguento a resignação. Ah, como devoro com fome e prazer a revolta.

Clarice Lispector (“As crianças chatas” - 1999, p. 23).

\title{
1. Introdução
}

$\mathrm{Na}$ esteira das citações acima, e que destaco como epígrafes deste artigo, proponho aqui reconhecer que na literatura de Clarice Lispector, sobretudo no que tange a sua produção no âmbito jornalístico, há um componente diferenciado. De modo especial, as crônicas que a escritora publicou no Jornal do Brasil entre as décadas de 60 e 70 trazem como conteúdo não apenas a representação efêmera do cotidiano, mas denuncia questões referentes aos problemas sociais mais graves, tais como a fome e a miséria.

Nesse sentido, vale lembrar que a trajetória de Clarice Lispector na imprensa perpassou toda a vida da escritora. Lispector relatava que, desde a infância, enviado textos para colunas infantis no Jornal de Pernambuco. Mas a escritora começou efetivamente as atividades na redação de um jornal por volta de 1940, no Rio de Janeiro, quando também era 
estudante da Faculdade de Direito. Na Agência Nacional iniciou uma atividade jornalística que se prolongaria por toda a sua vida, apesar de que com interrupções, conforme ressalta Gotlib: "Trabalha primeiramente como tradutora. (...) Posteriormente, é transferida da Agência Nacional para o jornal A Noite e lá passa a trabalhar como repórter, tendo como colegas muitos dos que também trabalhavam na Agência Nacional” (GOTLIB, 1995, p. 150).

O fato é que em 1967 iniciou um trabalho riquíssimo na publicação de crônicas semanais no Jornal do Brasil. O conjunto de textos que saíam aos sábados até o ano de 1973 foi reunido pelo filho da escritora, Paulo Gurgel Valente, no livro A descoberta do mundo, no ano de 1984. Entre a produção de romances como Água viva (1973) e A hora da estrela (1977), Lispector lança mão de seu espaço nas páginas do jornal para discutir sobre música, cultura, mas principalmente para destacar os incômodos por ela sentidos em face dos problemas sociais do Brasil num contexto de regime militar. De forma sutil, mas audaciosa, a escritora brasileira denuncia e faz de sua literatura caminhos para reflexão e mudança de perspectiva.

\section{Pensamento liminar e a proposta de um cronista perceptor}

Em Histórias locais / Projetos globais (2003), o argentino Walter Mignolo desenvolve a noção de pensamento liminar a partir da relação entre colonialidade e epistemologia, além da criticar a subalternização de conhecimentos por parte de um conhecimento hegemônico. Mignolo também reflete a respeito da existência de novos "loci" de pensamento e enunciação. Assim, é preciso lembrar que o início do século XVI foi marcado pelo processo de colonização dos países da América Latina, enquanto que no século XIX deu-se início ao processo de construção de nações após a independência da Espanha e de Portugal. Por causa disso, os saberes e as histórias locais da Europa acabaram sendo tomados como projetos globais, ou seja, o mundo colonial moderno foi tomado pelo conhecimento hegemônico europeu. Isso provocou uma subalternização de saberes, povos e culturas que não se enquadravam na proposta eurocêntrica.

As diferenças culturais eram ignoradas. Deste modo, e com base nessa consciência geopolítica das culturas, o autor propõe através do que ele chama de pensamento liminar uma nova epistemologia do saber. Isto é, o pensamento liminar parte do reconhecimento de novas epistemologias descentralizadas. Em outras palavras, trata-se de uma ruptura com o projeto cultural moderno em favor da iluminação e valorização de culturas e saberes antes subalternizados: 
O potencial epistemológico do pensamento liminar (...) tem a possibilidade de superar a limitação do pensamento territorial, cuja vitória foi possibilitada por seu poder de subalternizar o conhecimento localizado fora dos parâmetros das concepções modernas de razão e racionalidade (MIGNOLO, 2003, p. 102).

Conforme já dito, por causa da subalternização do conhecimento, muitos intelectuais influenciados pelo pensamento moderno acabam partilhando de uma visão preconceituosa e prepotente. Apenas determinados lugares, culturas e línguas tinham o direito ao pensamento crítico e a desenvolver qualquer reflexão científica. As consequências deste pensamento têm marcado os discursos de muitos acadêmicos e Instituições inteiras até hoje. Além disso, há um julgo pesadíssimo provocado pela colonialidade do poder e do saber que conduzem o pensamento do mundo pós-moderno à rotulação pelas aparências, pelas raças, pela diferença, sempre no sentido do baixo ou nenhum valor estético.

Nessa esteira, a concepção de pensamento liminar de Walter Mignolo emerge das histórias locais, na e a partir das margens o que, segundo o autor, "implica em pensar a partir de ambas as tradições, e, ao mesmo tempo, de nenhuma delas" (MIGNOLO, 2003, p. 102). A proposta é não fixar o pensamento, mas estabelecer diálogos críticos inclusive, e em constante movimento de troca.

O pensamento liminar possibilita reconhecer a diferença colonial e epistemológica, e dá espaço para a emergência de vozes, culturas e histórias que eram excluídas. Além disso, conforme suscita Frei Betto na epígrafe deste artigo, é preciso pensar "de onde" e "a quem" se dirige os relatos culturais referentes ao um lugar sociocultural, pois diante das diferenças há que se considerar a mudança de lugar epistêmico. Nas palavras de Mignolo (2003, p. 166), seriam os loci diferenciais, “onde as diferenças se relacionam com o originar-se de diferentes heranças coloniais e estar em diferentes locais geoculturais".

Tendo em vista estas reflexões e reconhecendo a ligação entre o gênero literário da crônica e o cotidiano, ocorreu-me pensar a respeito da percepção de Clarice Lispector no que tange a esta ruptura com a proposta cultural do pensamento moderno em suas crônicas reunidas no livro A descoberta do mundo. Nesse sentido, se pensarmos no sujeito baudelairiano, que é chamado de flâneur pelo seu caráter peculiar de observador da vida urbana, vale destacar as palavras de Charles Baudelaire que explica a dimensão da essência desse flâneur: 
Para o perfeito flâneur, para o observador apaixonado, é um imenso júbilo fixar residência no numeroso, no ondulante, no movimento, no fugidio e no infinito. Estar fora de casa, e contudo sentir-se em casa onde quer que se encontre; ver o mundo, estar no centro do mundo e permanecer oculto ao mundo, eis alguns dos pequenos prazeres desses espíritos independentes, apaixonados imparciais, que a linguagem não pode definir senão toscamente. (BAUDELAIRE, 1996, p. 19-20)

Há em comum entre o flâneur baudelairiano e a cronista Clarice Lispector exatamente o fato de estar no centro do mundo e (querer) permanecer oculto ao mundo, pois sabemos que Lispector preferia o prazer do "anonimato" e a liberdade em falar sobre o que quisesse a viver sob o filtro do cânone e da fama. Também há em comum a percepção do múltiplo, já que no flâneur existe o interesse em absorver toda e qualquer manifestação cultural a cada passo dado especialmente nos ambientes urbanos. A diferença, entretanto, está evidentemente no lugar sociocultural e na construção individual do observador, ou seja, na sua própria história local que faz com que este o perceba conforme este lugar epistêmico.

Mas para ir além nesta reflexão, é interessante destacar o ensaio "Culpas e memórias nas modernidades locais" (2009) no qual Hugo Achugar reflete sobre a questão de um "olhar diferenciado" no contexto latino-americano se comparado com compreensão analítica de Walter Benjamin em torno do flâneur. A partir disso, Achugar "divaga" (como sugere o subtítulo do ensaio) sobre os olhares de Benjamin em torno da temática do consumo e dos meios de transporte na pós-modernidade. Porém, o que de fato interessa neste ensaio é que Achugar inicia a discussão tratando sobre a relação entre velocidade e modernidade.

Em outras palavras, o autor uruguaio aponta para uma possível transversalidade das modernidades a partir da multitemporalidade na qual se desenvolveram as heterogêneas histórias latino-americanas: "Falo da velocidade não apenas como uma forma de deslocamento, mas também na velocidade com relação à propensão à mudança, à aceitação do novo ou diferente" (ACHUGAR, 2009, p. 15). O que novamente nos remete às palavras de Frei Betto - todo ponto de vista é a vista a partir de um ponto -, mas, sobretudo, reforça a necessidade prática do pensamento liminar proposto por Mignolo.

Ora, a percepção do homem está ligada à perspectiva a partir da qual se vê, e esta perspectiva, por sua vez, depende de deslocamentos, ou seja, das mudanças de lugar e de pontos de vista, para que então se possa ver o que não se percebe de um ponto fixo. Assim, é possível concluir, por exemplo, que a concisão da crônica favorece o olhar diferenciado do cronista. Achugar, esclarece que esse escritor seria imbuído de um olhar diferenciado por trazer consigo um grau de peculiaridade histórica e local, porque "não se trata de um registro 
dos meios de deslocamento da modernidade, mas de outro tipo de registro, de outro tipo de olhar" (ACHUGAR, 2009, p. 18). Portanto, ao escritor que se apropria ou que naturalmente nutre sua narrativa com este olhar diferenciado chamo de escritor perceptor.

No entanto, antes de me aprofundar neste termo que proponho, e para relacionar este escritor diferenciado, no caso Clarice Lispecor, à produção literária através da crônica, retomo a noção de velocidade, inicialmente abordada por Achugar, e a associo à rapidez ou efemeridade deste gênero oriundo dos jornais.

\subsection{A crônica: $o$ gênero das mobilidades epistemológicas}

Davi Arrigucci Jr. (1987) destaca o fato de que todos os significados apontados para a palavra crônica implicam a noção de tempo (chronos, do grego, tempo), e por isso ele acredita que "muito próximo do evento miúdo do cotidiano, o cronista deve de algum modo driblá-lo, se não quiser naufragar agarrado ao efêmero" (ARRIGUCCI Jr., 1987, p. 55). Isso porque a crônica, principalmente no final do século $\mathrm{XX}$, era um tipo de texto geralmente publicado diária ou semanalmente no âmbito jornalístico, e que apenas por meio da organização de livros ou coletâneas poderia digamos que "eternizar-se" enquanto obra literária.

A brevidade e a concisão marcam representativamente as principais características do gênero, haja vista que o espaço no jornal para o texto e o tempo do leitor pós-moderno apontam para a velocidade de que fala Hugo Achugar no ensaio anteriormente mencionado. Corrobora ainda o pensamento de Ítalo Calvino quando inclui a rapidez como uma de suas propostas para o que seria o próximo milênio: "Nos tempos cada vez mais congestionados que nos esperam, a necessidade de literatura deverá focalizar-se na máxima concentração da poesia e do pensamento" (CALVINO, 1990, p. 63).

Para Calvino, não se trata apenas de pensar numa velocidade física, mas em relacionar a velocidade física e a velocidade mental. E eu diria que isto é possível quando o intelectual que percebe as manifestações culturais ao seu redor tem vínculo, repito, com o local da cultura em questão e que se reconheça nele.

Um exemplo no qual se pode notar esta relação entre velocidade física e velocidade mental está na crônica "As crianças chatas", de 1967, e que destaquei como segunda epígrafe deste artigo. Trata-se de uma narrativa composta por um único parágrafo (velocidade física), mas de tamanha profundidade e proximidade com o real - ou o que podemos chamar de experiência compartilhada - que é capaz de conduzir o leitor 
imediatamente a vislumbrar a cena descrita (velocidade mental). O texto sugere esta mudança de lugar epistêmico. O tema da fome, que será tratado nas próximas páginas deste artigo, é uma constante nas crônicas clariceanas e, pela pungência, conduz o leitor à reflexão em torno de um problema pouco debatido por não estar nos "planos" do projeto cultural moderno.

No único parágrafo que compõe a referida crônica é possível perceber o mergulho que a cronista faz no processo de captura de seu referente. $\mathrm{O}$ texto foi a primeira crônica publicada por Lispector no Jornal do Brasil, por isso abre a coletânea A descoberta do mundo. O livro já começa com um "Não". A repetição do advérbio de negação na primeira linha da crônica - Não posso. Não posso pensar na cena que visualizei e que é real - reforça o caráter denunciativo no discurso da cronista que, por sua vez, não aceita a realidade e não pretende passar pela cena indiferentemente. Nota-se que há uma recusa em compactuar com a situação de um filho que pede comida à mãe que nem o "não" tem para oferecer. Tanto é que, como resposta, a personagem pede para que a criança durma. Nesse sentido, com base na resposta da mãe, Clarice Lispector interpreta esta reação atribuindo à cena a expressão "ninho da resignação". Ora, é exatamente a resignação, enquanto oposição ao sentido de revolta, que incomoda a cronista perceptora.

A criança no texto também resiste ao pedido da mãe para que ele durma: Não posso, estou com fome. Por conseguinte, nesta crônica, "As crianças chatas", a ação de manifestar-se contra no discurso clariceano atinge o seu ápice na última linha do texto: "E eu não aguento a resignação. Ah como devoro com fome e prazer a revolta" (LISPECTOR, 1999, p. 23). A palavra "devorar" revela a ferocidade com que a Clarice Lispector cronista lida com o instintivo senso de valor humano, além do forte desejo de trazer à tona uma situação que pouco comove a população resignada. É como se a narradora trancasse os dentes para dizer as últimas palavras. Mas, sobretudo, é como se ali a escritora perceptora fizesse seu pronunciamento categórico e resistente à maneira com que a sociedade e os meios institucionais e governamentais lidam com a situação: eu não aguento a resignação.

Contudo, para melhor aliar a ideia de pensamento liminar e de cronista perceptor às crônicas de Clarice Lispector, sobretudo no que tange o tema da fome, é preciso também reconhecer que Lispector esta se personifica enquanto parte daquilo que escreve. Portanto, para além do intelectual observador, há o vínculo pela percepção, daí a expressão perceptor. A percepção exige o vínculo daquilo que, de perto ou de longe, esteja imbuído no íntimo do intelectual a partir de suas experiências.

\subsection{O olhar diferenciado do escritor perceptor}


A palavra "perceber" é de origem latina, percipere, e originalmente significa "pegar com a mente" (percapere: pegar, agarrar, compreender). É como se pela identidade cultural local fosse desperta no escritor uma familiaridade associada à construção do sujeito em si. Assim, o escritor "pega", agarra para si e para junto da própria experiência os fatos externos de acordo com aquilo que lhe é humanamente reconhecido. O local da cultura e pertencimento está refletido na identidade do sujeito e, no caso da crônica, esta deve ser vista mais que como um registro do circunstancial ou fugidio, mas trata-se da percepção do intelectual que se permite deslocar epistemologicamente falando.

Deste modo, para tratar a respeito da presença do elemento biográfico-cultural nas crônicas de Clarice Lispector, me valho do pensamento de Eneida de Souza ao explicar que o objetivo da crítica biográfica não é o de reduzir a obra à existência do autor ou afirmar que a ficção é um produto da vivência pessoal deste autor, mas que "as relações teóricoficcionais entre obra e vida resultam no desejo de melhor entender e demonstrar o nível de leitura do crítico, ao ampliar o polo literário para o biográfico e daí para o alegórico" (SOUZA, 2011, p. 21). O crítico encontra sua vida não só no que lê, mas também no que vê, no que ouve, no que percebe. Depois, o escritor projeta esta percepção no texto literário para então convidar o leitor a alcançar percepções a partir do lugar sociocultural em que se encontra. Vale lembrar que, no caso da crônica, o autor assina o próprio texto marcando não apenas a presença autoral, mas também de proximidade com o que se discute.

Portanto, e seguindo este raciocínio, é desta forma que se manifesta a cronista perceptora Clarice Lispector. Conforme o comentário de Nádia Gotlib sobre A hora da estrela (1977), também nas crônicas a manifestação de Clarice Lispector se dá principalmente "sob a forma de grito de rebeldia, denunciando a fome e a impotência das personagens, ela também prisioneira como os macabeus, mas que, como eles, resiste, nordestina na cidade grande, massacrada por um sistema social desumano" (GOTLIB, 1995, p. 66). A escritora perceptora parece estar mais próxima à nossa realidade do que se imagina. Principalmente no sentido de que ela se despoja das condecorações para estar mais perto do marginal e do periférico do que do institucional e do acadêmico.

Portanto, diferentemente das perspectivas infrutíferas pautadas na busca por precursores e vínculos de dependência, faz-se necessário reconhecer no perfil perceptor do escritor os vínculos pela pertença local e sociocultural para então identificar em sua literatura o caráter a) humanizador e b) não rotulável. 
Humanizador porque a percepção é própria do sujeito, mas marcada pelas experiências e pelas diferenças culturais, o que sensibiliza e conduz o outro à percepção do ser diferente e de outros lugares epistêmicos. No entanto, vale destacar que ninguém definiu melhor a função humanizadora da literatura que Antonio Candido no ensaio "O direito à Literatura":

Entendo aqui por humanização o processo que confirma no homem aqueles traços que reputamos essenciais, como o exercício da reflexão, a aquisição do saber, a boa disposição para com o próximo, o afinamento das emoções, a capacidade de penetrar nos problemas da vida, o senso da beleza, a percepção da complexidade do mundo e dos seres, o cultivo do humor (CANDIDO, 2011, p. 182 - grifos meus.).

Por conseguinte, o escritor perceptor também não é rotulável pelo mesmo motivo que o conduz à produção literária naturalmente humanizadora. Ou seja, por ser própria de cada sujeito ela é livre, porém aberta às análises no estudo de grupos culturais os quais partilham das mesmas experiências locais. Livre de rótulos, as literaturas marcadas pela diferença poderão dialogar com outras literaturas inclusive já imortalizadas pela academia (o cânone). Isso ampliaria o leque de possibilidades na análise e compreensão do lugar cultural epistêmico em que as literaturas são produzidas.

Vale lembrar que, em entrevista concedida por Clarice Lispector à TV Cultura, no ano de 1977, a escritora é questionada sobre quando teria assumido a "carreira" como escritora. A resposta surpreende, mas faz jus ao perfil perceptor de Lispector: "Eu nunca assumi. Eu não sou uma profissional. Eu só escrevo quando eu quero. Eu sou uma amadora. (...) Eu faço questão de não ser uma profissional, pra manter minha liberdade" (sic) (LISPECTOR apud GOTLIB, 1995, p. 454).

\subsection{O intelectual e a consciência da fome}

Por conseguinte, faz-se necessário compreender que a fome enquanto problema social coletivo representa a ausência de poder daquele que a sente. Assim, no que se refere ao poder, Michel Foucault (2014, p. 39) explica que a questão está naquilo que rege os enunciados para serem consideradas propostas "aceitáveis" cientificamente. Isto é, a questão não é saber se há um poder externo que possa influir na ciência, mas quais os efeitos de poder que regem internamente os enunciados científicos de modo que estes sejam capazes de modificar globalmente esta noção de poder. Nesse sentido, Foucault (2014, p. 40) explica ainda que, apesar das tentativas estruturalistas de eliminar o conceito de acontecimento, não 
se pode colocar tudo num certo plano, mas levar em consideração o fato de que existem acontecimentos diferentes. Por isso ficam evidentes as relações de poder entre os níveis identificáveis pela diferença, principalmente nas diferenças epistemológicas.

Por esse prisma, surgem, portanto, as reflexões em torno do intelectual. De acordo com Foucault, ser intelectual significou por um tempo ser a consciência de todos ou o representante do universal: "o intelectual seria a figura clara e individual de uma universalidade da qual o proletariado seria a forma obscura e coletiva" (FOUCAULT, 2014, p. 46). Mas isso mudou e o intelectual passou, portanto, a trabalhar em determinados setores da sociedade, fazendo com que este tome consciência das lutas e dos diferentes problemas sociais, distantes, inclusive, das massas. É o que Foucault chama de intelectual específico em oposição ao intelectual universal, e explica: "Essa figura nova tem outra significação política: permitiu se não soldar, pelo menos rearticular categorias bastante vizinhas, até então separadas" (FOUCAULT, 2014, p. 47). A partir disso, o autor diz ser o escritor o mais próximo do intelectual universal, por ser portador de significações e de valores, do que do intelectual específico.

Assim, talvez seja possível afirmar que por esse motivo Clarice Lispector nunca quis se assumir como "escritora profissional", por exemplo. A escritora queria preservar sua liberdade de falar sem ter a obrigação de que todos se reconhecessem em suas narrativas. São outras vistas a partir de um ponto. Nesse sentido, a escritora propõe debates em torno da figura do escritor, conforme consta em livro de Olga Borelli, umas das amigas íntimas de Lispector: "Há escritores (...) cuja literatura é dirigida ou planificada a fim de exaltar valores, geralmente impostos por poderes políticos, religiosos, etc., muitas vezes alheios ao escritor" (LISPECTOR apud BORELLI, 1981, p. 73). Por isso, Lispector propõe ainda uma forma de conduzir o leitor ao pensamento crítico ao defender que a literatura deve fazer com que o leitor reflita e questione sobre o sentido e destino do homem no mundo e de que modo este homem pode contribuir para a vida em sociedade, especialmente no seu lugar sociocultural.

Nesse sentido, retomando o pensamento de Foucault, o filósofo aponta para a necessidade de se reelaborar a função do intelectual específico, exatamente por estar atrelado ao fato de que este novo intelectual corre o risco de criar discursos excludentes, sobretudo se forem potencializadas as especificidades: "Seria perigoso desqualificá-lo em sua relação específica com um saber local, sob pretexto de que se trata de um problema de especialistas que não interessa às massas (...) ou ainda de que ele veicula uma ideologia cientificista" 
(FOUCAULT, 2014, p. 51). Ora, de acordo com Foucault, surge a necessidade que haja a ruptura com o universal para que se abram as portas e dê lugar para o local e o marginal.

Isso porque, a partir das relações de diferenças, é possível identificar as especificidades de cada lugar epistemológico, graças a uma tomada de consciência por parte do escritor intelectual. Principalmente quando identifico, por exemplo, o aspecto perceptor que, pela produção literária, vincula e humaniza tanto o intelectual quanto o leitor.

Dialogando com Foucault, em certa medida, Edward Said (2005) explica que há na modernidade dois tipos de intelectuais: o primeiro seria um grupo dos intelectuais tradicionais, composto por professores e clérigos, e, o segundo, composto pelos intelectuais orgânicos, ligados às classes ou empresas e usados para garantir interesses e maior poder. Sob esta perspectiva, antecipadamente é possível entender que um dos fatores que irritavam Clarice Lispector no que se refere ao ser intelectual era o fato de que talvez ela estivesse sendo representada como uma "intelectual orgânica" e que, por sua vez, deveria satisfazer as necessidades do mercado caso tomasse posse de tal rótulo. Voltando à entrevista ao programa Panorama, da TV Cultura, nota-se uma sequência interessante onde Lispector parece refletir sobre o ser intelectual no Brasil da década de 70:

P. - Normalmente, que tipo de problema a Clarice Lispector-escritora traz a você?

C.L. - Às vezes o fato de me considerarem escritora me isola.

P. - Por qual razão?

C.L. Me põem um rótulo.

P. E você acredita que as pessoas olhem para você através desse rótulo?

C.L. Às vezes só através desse rótulo. Tudo o que eu digo, ou não é a maior bobagem... E então é considerada como uma coisa linda, ou uma coisa boba. Tudo na base de ser escritora. É por isso que eu não ligo muito para essa coisa de ser escritora e dar entrevista e tudo. É porque eu não sou isso. (apud GOTLIB, 1995, p. 459).

Assim, diante de uma possível confusão na representação do intelectual, Edward Said afirma que: "Os verdadeiros intelectuais constituem uma clereza, são criaturas de fato muito raras, uma vez que defendem padrões eternos de verdade e justiça que não são precisamente deste mundo" (SAID, 2005, p. 21). A contraproposta de Clarice Lispector ao denunciar o problema da fome, por exemplo, num período que compreende a ditadura militar no Brasil sinaliza o anseio pela verdade e principalmente pela justiça para com os miseráveis.

Conforme frisa Said, o verdadeiro intelectual não é alheio ao mundo. Não são "fechados numa torre de marfim", mas são movidos por princípios desinteressados de justiça e verdade: "denunciam a corrupção, defendem os fracos, desafiam a autoridade imperfeita ou opressora" (SAID, 2005, p. 21). Para ele, portanto, o intelectual não pode ser reduzido a um 
"profissional sem rosto", pois se trata de um indivíduo com grande vocação para apresentar pontos de vista, articular ideias e atitudes. Mas, sobretudo, o verdadeiro intelectual é capaz de correr riscos ao enfrentar grupos de poder por uma causa: "O que o intelectual menos deveria fazer é atuar para que seu público se sinta bem: o importante é causar embaraço, ser do contra e até mesmo desagradável” (SAID, 2005, p. 27). Sendo assim, o intelectual é aquele que parte de um incômodo para também incomodar.

Portanto, Clarice Lispector cumpre seu papel de alinhar-se aos fracos. $\mathrm{Na}$ crônica "Intelectual? Não.", Lispector rejeita o caráter intelectual (orgânico), conforme se nota já no título, mas explica que o modo como o mundo enxerga o intelectual é limitado demais para contemplar sua percepção do mundo: "Sou uma pessoa que tem um coração que por vezes percebe, sou uma pessoa que pretendeu pôr em palavras um mundo ininteligível e um mundo impalpável” (LISPECTOR, 1999, p. 149 - grifo meu). E aqui se confirma que por trás do intelectual e, sobretudo, por trás do discurso crítico está o escritor perceptor.

\section{O grito da fome: crônicas de dentes trancados}

\footnotetext{
Não escrevo sobre problemas sociais, mas eu os vivo intensamente e, já em criança, me abalava inteira com os problemas que via ao vivo.

Clarice Lispector (1999, p. 309).
}

Nos tópicos anteriores apresentei a crônica "As crianças chatas", que abre a coletânea A descoberta do mundo. O forte indício de que Clarice Lispector estava empenhada em não poupar esforços, tampouco palavras, para manifestar sua revolta em face da fome e da miséria aparece já nas primeiras páginas do livro. E, diga-se de passagem, em boa parte dos textos a escritora sempre aproveita as oportunidades que seus peculiares momentos de inspiração lhe oferecem, bem como os diálogos com outros intelectuais, para tratar do assunto de forma severa.

No livro Geografia da fome, resultado de levantamento feito por Josué de Castro em meados da década de 40, o autor aponta o mapa da fome no Brasil. Castro, já na introdução do livro, assimila que, quando se trata da fome, imediatamente imaginamos os países do Extremo Oriente ou, naquele tempo, nos campos de concentração nazistas. Porém, nenhum continente escapa à ação das crises pela falta de alimento: "Mesmo nosso continente, chamado do tal da abundância e simbolizado até hoje nas lendas do Eldorado, sofre intensamente o flagelo da fome" (CASTRO, 1969, p. 36). Do mesmo modo, nenhuma região 
do Brasil escapa aos problemas relacionados à fome. Por isso, o autor também desconstrói a ideia de que a fome no Brasil é uma realidade que atinge unicamente as regiões norte e nordeste ou cidades interioranas e vilarejos. Para Castro (1969, p. 38), as causas fundamentais do que ele chama de "alimentação defeituosa" "são mais produto de fatores socioculturais do que de fatores de natureza geográfica”. Assim, também as outras regiões do país sofriam com a fome no final da década de 40.

No caso da região sudeste, na qual se insere o estado do Rio de Janeiro, que, por sua vez, seria cenário da maior parte das crônicas de Clarice Lispector nos anos 60, é considerada por Castro a região onde a fome se manifestava de forma mais "discreta ou oculta". Contudo, marcada pela subnutrição, a região também apresentava carências graves:

Uma delas se manifesta, no entanto, de forma gritante: é a carência de proteínas
entre as crianças pobres dos grandes centros urbanos da região. Em cidades como a
do Rio de Janeiro e São Paulo os pediatras têm constatado nos últimos anos uma
incidência extremamente alta dos edemas de fome, das distrofias malignas e mesmo
dos síndromes típicos de "kwaskiokor" (sic) entre as crianças atendidas nos
hospitais públicos, nos bairros operários e nos subúrbios (CASTRO, 1969, p. 260-1).

E aqui chegamos ao ponto que mais nos interessa: as crianças famintas, tão recorrentemente representadas nas crônicas de Clarice Lispector, conforme vimos em "As crianças chatas", publicada no Jornal do Brasil em 1967.

O que Josué de Castro aponta como sendo um problema gritantemente preocupante já na década de 40 parece não ter se resolvido, mas se agravado, não só no Brasil, mas em toda a América Latina no final dos anos 70. Segundo Eduardo Galeano, em As veias abertas da América Latina, em 1978 havia mais de 120 milhões de crianças "no centro da tormenta" e a população passou a crescer muito: "A cada minuto morre uma criança de doença ou de fome, mas no ano 2000 haverá 650 milhões de latino-americanos, e a metade terá menos de 15 anos de idade: uma bomba-relógio" (GALEANO, 2016, p. 20).

Nesse sentido, Clarice Lispector define, se é que posso usar esta expressão, a sensação da fome nas poucas linhas que compõem a pequena crônica intitulada "A fome", de setembro de 1968: "Meu Deus, até que ponto vou na miséria da necessidade: eu trocaria uma eternidade de depois da morte pela eternidade enquanto estou viva" (LISPECTOR, 1999, p. 139). Para a cronista, a dor da fome e de precisar suprir necessidades é o fator principal para que se possa viver plenamente, a ponto de se alcançar a eternidade em vida. Nota-se nas crônicas clariceanas que não há limites para o escritor perceptor que pretende ir até as últimas consequências para denunciar as desigualdades sociais que culminam com a miséria. Isso 
porque, a indiferença era a principal causa do índice elevado de mortalidade infantil naquele período bem como outros problemas relacionados à pobreza.

Na crônica "Entrevista alegre", de 1967, Lispector fala sobre uma entrevista concedida a jornalista Cristina naquele mesmo ano. Em certa altura, verifica-se a crítica da escritora a respeito da cultura popular, que parece não contribuir para a conscientização com relação à miséria, conforme se nota no trecho destacado:

Perguntou-me o que eu achava da cultura popular. Eu disse que ainda não existe propriamente. Quis saber se eu a considerava importante. Eu disse que sim, mas que havia algo muito mais importante ainda: oferecer oportunidade de ter comida a quem tem fome. A menos que a cultura popular leve o povo a tomar consciência de que a fome dá o direito de reivindicar comida (LISPECTOR, 1999, p. 60-1).

Outro exemplo no qual se identifica o discurso denunciativo de Clarice Lispector em torno da fome é a crônica intitulada "Daqui a vinte e cinco anos", de setembro do mesmo ano. Neste texto, a escritora relata em primeira pessoa que foi convidada a pensar o futuro do Brasil em vinte e cinco anos. Apesar de deixar claro que seria incapaz de tal premonição, Lispector elenca as prioridades a serem postas em prática no tocante à vida em sociedade. A primeira delas, segundo a escritora, é a necessidade de que a população se manifeste por si: "Daqui a vinte e cinco anos o povo terá falado muito mais" (LISPECTOR, 1999, p. 33). Nota-se que o desejo de Clarice Lispector, mais do que se manifestar enquanto perceptora, está em conduzir o leitor e a população em geral a uma tomada de consciência e percepção, para também soltar o próprio grito. Para a escritora a situação da fome é tão grave que seria o caso de decretar estado de prontidão e calamidade pública:

Posso intensamente desejar que o problema mais urgente se resolva: o da fome. Muitíssimo mais depressa, porém, do que em vinte e cinco anos, porque não há mais tempo de esperar: milhares de homens, mulheres e crianças são verdadeiros moribundos ambulantes que tecnicamente deviam estar internados em hospitais para subnutridos. (...) Só que é pior: a fome é a nossa endemia, já está fazendo parte orgânica do corpo e da alma. (LISPECTOR, 1999, p. 33)

No trecho, mais uma vez fica clara a inconformidade de Lispector em relação à estagnação das autoridades e dos povos perante a fome. A escritora analisa o problema como uma doença social já em caráter endêmico e quase sem solução. E, nas linhas subsequentes, é possível estabelecer também um contraponto com uma fala de Clarice Lispector para Cristina na "Entrevista alegre".

Refiro-me à lucidez com que a escritora assimila a fome física, enquanto necessidade do corpo, à fome cultural e cognitiva. Um povo faminto não tem forças para 
reivindicar direitos básicos, morais e intelectuais, conforme Lispector sugere: "Na maioria das vezes, quando se descrevem as características físicas, morais e mentais de um brasileiro, não se nota que na verdade se estão descrevendo os sintomas físicos, morais e mentais da fome" (LISPECTOR, 1999, p. 33). O brasileiro é faminto e sedento em todos os sentidos, pois a falta de comida afeta sua capacidade de se reconhecer enquanto indivíduo pensante.

Mas Clarice Lispector, ao final de suas crônicas, sempre tranca os dentes para arrematar o seu discurso com a máxima convicção por meio de palavras valorativas e impactantes: "Os líderes que tiverem como meta a solução econômica do problema da comida serão tão abençoados por nós como, em comparação, o mundo abençoará os que descobrirem a cura para o câncer" (LISPECTOR, 1999, p. 33). Para atribuir a devida seriedade ao problema, Lispector reforça a noção de fome enquanto doença (grave) e incurável da sociedade, mas de forma muito direta aponta as autoridades do país como sendo os primeiros que deveriam se posicionar em face ao problema.

Para a escritora, parece inacreditável que um ser humano não se compadeça de outro que se encontre em situação de miserabilidade. Não há desejo de vínculo, tampouco de compaixão Apesar de destacar a falta de comida para homens, mulheres e crianças, Clarice Lispector parece revoltar-se mais quando se trata das crianças. Isso porque em outras crônicas, sempre que há uma oportunidade na qual caiba lembrar os pequenos famintos, Lispector lembra.

Assim, a crônica “Quando chorar”, de novembro 1967, traz nos três parágrafos que compõem o texto a descrição do processo de comoção provocado pelo choro de outra pessoa que passa fome. Inicialmente, a narradora afirma que há uma diferença entre o choro bom e o choro ruim, e explica que o choro bom dá alívio, enquanto que o choro ruim só faz cansar e exaurir o sujeito em prantos. A cronista então relata: "Uma amiga perguntou-me, então, se não seria esse choro [o ruim] como o de uma criança com a angústia da fome. Era. Quando se está perto desse tipo de choro, é melhor procurar conter-se: não vai adiantar" (LISPECTOR, 1999, p. 47).

Ao identificar que o choro ruim é aquele que não sacia a alma, pois resulta da fome, a narradora personagem do texto alerta a interlocutora (a amiga), bem como o leitor, de que se trata de uma situação na qual seja impossível não se comover. Por conseguinte, a cronista explica que não faz mal abrir espaço a uma tristeza que ela chama de legítima, porque ser produto da dor profunda. A esse tipo de ação pela compaixão, Clarice Lispector não resiste e sugere também que não haja resistência diante da dor do outro: "Nem sempre é necessário tornar-se forte. Temos que respeitar a nossa fraqueza” (LISPECTOR, 1999, p. 47). 
Respeitar as fraquezas significa também não resignar-se, sendo o choro, portanto, uma forma natural de manifestar-se contra algo.

Por esse prisma, é também possível compreender o que Lispector afirma na crônica "Em busca do outro", de 1968: "Quando eu puder sentir plenamente o outro estarei salva e pensarei: eis o meu porto de chegada" (LISPECTOR, 1999, p. 119). Para o escritor perceptor, o porto de chegada está naquilo que o vincula ao outro no lugar sociocultural no qual está inserido. Enquanto a maioria das pessoas busca o autoconhecimento em si mesmo, Clarice Lispector buscar encontrar-se no outro semelhante a ela para então manter contato com os diferentes lugares epistêmicos.

Com o passar dos anos de contribuição para com o Jornal do Brasil, a maturidade escritural de Clarice Lispector atinge o ponto em que suas crônicas ganham uma variabilidade maior de temas em textos também mais longos. O contato com artistas, cantores e intelectuais da época fez com que ela publicasse também relatos de encontros e diálogos a respeito de música, esporte e cultura em geral - tudo isso em forma de crônica. Mas a escritora não abandona por completo o seu plano de projetar a atenção do público para as questões sociais. Na crônica "Eu tomo conta do mundo", de março de 1970, Lispector parece dizer que de modo algum se esqueceu daqueles que, ao contrário dos artistas e intelectuais, não são famosos.

Sou uma pessoa muito ocupada: tomo conta do mundo, são as primeiras palavras da crônica, sempre sob o olhar atento da perceptora Lispector, e cuja beleza literária encanta o leitor pelo jogo de palavras com excessos de adjetivos que caracterizam a cidade do Rio de Janeiro vista de um terraço: o mar, a praia, os monumentos, o Jardim Botânico: "Todos os dias olho pelo terraço para o pedaço de praia com mar, e vejo ás vezes que as espumas parecem ser mais brancas e que ás vezes durante a noite as águas avançaram inquietas, vejo isso pela marca que as ondas deixaram na areia" (LISPECTOR, 1999, p. 275).

Contudo, do terraço também é possível ver - e a escritora faz questão de trazer isso para o "campo visual do leitor", com a mesma consistência linguística - as ruas, as calçadas e as favelas. O que talvez não seja de tão agradável visão:

Observo o menino de uns dez anos, vestido de trapos e magérrimo. Terá futura tuberculose, se é que já não a tem. (...) E lembro-me de um rosto inexpressivo de uma mulher que vi na rua. Tomo conta dos milhares de favelados pelas encostas acima (LISPECTOR, 1999, p. 276).

Nota-se o contraste propositalmente exposto pela cronista ao destacar não apenas as belezas da cidade do Rio de Janeiro, mas também os reflexos de uma má organização econômico- 
social. A passagem nos permite ainda pensar que a "criança chata" continua com fome, e que a estagnação no rosto inexpressivo da mulher também confirma a sobrevivência resignada. A impressão que se tem é que a escritora perceptora Clarice Lispector sustenta seu incômodo em face das desigualdades sociais na medida em que não vê mudanças significativas neste cenário. Mas o alerta está feito.

\section{Considerações finais}

A questão social em Clarice Lispector é algo que não está representado apenas na figura de Macabéa em A hora da estrela. O projeto escritural de Lispector em suas crônicas talvez não seja um projeto, mas a percepção em fluxo semanal dos fatos cotidianos sob o olhar atento de uma cronista que se permite vincular àquilo que pode ser pungente para a maior parte da população, mas que não pode ser jogado para debaixo do tapete.

$\mathrm{Na}$ crônica, sabemos que o cronista se revela por ser aquele que assina a coluna, assumindo, portanto, a responsabilidade daquilo que se denuncia. Lispector costumava dizer que era "tímida e ousada ao mesmo tempo", o que nos leva a crer que nas crônicas imperava a ousadia clariceana, pois o país encontrava-se naqueles anos sob o redime ditatorial militar. Mas é preciso destacar na escritora, sobretudo, a consciência de que, como suscita Frei Betto, a mudança de ponto de vista exige a mudança de lugar epistêmico: "Dito de outro modo, o lugar sociocultural do leitor influi na hermenêutica do texto" (BETTO, 2017, p. 97). E a condução feita por Lispector nas crônicas faz com que o leitor reconheça as diferenças de lugar e saber epistemológicos no entorno social.

\section{REFERÊNCIAS}

ACHUGAR, Hugo. Culpas e memórias nas modernidades locais: divagações a respeito de "O flâneur" de Walter Benjamin. Trad. Rômulo Monte Alto. In: SOUZA, Eneida Maria de; MARQUES, Reinaldo [Org.]. Modernidades alternativas na América Latina. Belo Horizonte: Editora UFMG, 2009. p. 14-31.

ARRIGUCCI Jr., Davi. Fragmentos sobre a crônica: Literatura, exílio e utopia. In: Enigma e comentário: ensaios sobre literatura e experiência. São Paulo: Companhia das Letras, 1987. p. 51-66.

BAUDELAIRE, Charles. Sobre a modernidade: o pintor da vida moderna. Trad. e Org. Teixeira Coelho. Rio de Janeiro: Terra e Paz, 1996. (Coleção Leitura) 
BORELLI, Olga. Clarice Lispector: esboço para um possível retrato. Rio de Janeiro: Nova Fonteira, 1981.

CALVINO, Ítalo. Seis propostas para o próximo milênio. Trad. Ivo Barroso. 2 ed. São Paulo: Companhia das Letras, 1990.

CANDIDO, Antonio. O direito à literatura e Outros ensaios. 5 ed. Rio de Janeiro: Ouro Sobre Azul, 2011.

CASTRO, Josué. Geografia da fome: o dilema brasileiro - pão ou aço. 11 ed. São Paulo: Brasiliense, 1969.

FOUCAULT, Michel. Microfísica do poder. 28 ed. Rio de Janeiro: Paz e Terra, 2014.

FREI BETTO. Ofício de escrever. Rio de Janeiro: Anfiteatro, 2017.

GALEANO, Eduardo. As veias abertas da América Latina. Trad. Sérgio Faraco. Porto Alegre: L\&PM, 2016.

GOTLIB, Nádia Battela. Clarice: uma vida que se conta. São Paulo: Ática, 1995.

LISPECTOR, Clarice. A descoberta do mundo. Rio de Janeiro: Rocco, 1999.

MIGNOLO, Walter. Histórias locais/Projetos globais: colonialidade, saberes subalternos e pensamento liminar. Trad. Solange Ribeiro de Oliveira. Belo Horizonte: Editora UFMG, 2013.

SAID, Edward. Representações do intelectual. São Paulo: Companhia das Letras, 2005.

SOUZA, Eneida Maria. Janelas indiscretas: ensaios de crítica biográfica. Belo Horizonte: Editora UFMG, 2011. 